\title{
Perhitungan Penghematan Energi Terhadap Rencana Pemasangan Automatic Blowdown Control System Pada HOKEN Boiler
}

\author{
Meijon Pelayer ${ }^{1}$, Dikpride Despa ${ }^{2}$ \\ ${ }^{1}$ Pemerintah Daerah Kabupaten Ogan Komering Ulu \\ ${ }^{1}$ Jl. Kemelak Bindung Langit, Batu Raja Timur, Ogan Komering Ulu, Sumatera Selatan 32111 \\ ${ }^{1}$ meijon1977@gmail.com
}

\begin{abstract}
Intisari - Boiler Feed water dengan tidak mengindahkan jenis dan luasnya masih terdapat contaminant contaminant yang dapat menyebabkan pengendapan, korosi dan carry over. Pengendapan secara langsung berkaitan dengan menurunnya efektifitas perpindahan panas yang menyebabkan pemborosan penggunaan bahan bakar. Kandungan padatan terlarut dalam air boiler (dalam bentuk TDS, total dissolved solid) semakin tinggi dengan penguapan air boiler menjadi steam. Kandungan padatan terlarut ini dapat mangakibatkan priming dan carry over air boiler menuju aliran steam bila dibiarkan secara terus menerus. Hal ini dapat mengakibatkan kerusakan pada jalur steam dengan adanya waterhammer, korosi dan kotoran yang menghambat laju pindah panas. Untuk mencegah tingginya kandungan padatan terlarut dalam air boiler, pembuangan air dilakukan melalui blowdown valve sehingga feed water dapat segera terganti dengan baik. Namun pengendalian blowdown secara terus menerus dengan range waktu yang cukup lama dapat menyebabkan kehilangan air boiler, energi, bahan kimia dan biaya lainnya. Umumnya selama ini, blowdown dilakukan secara manual atau dengan timer secara berkala (misal 1 jam selama 3 - 15 detik) cara ini diyakini telah menghasilkan pemborosan blowdown, karena blowdown tetap dilakukan meskipun kondisi air boiler masih dalam kondisi bagus (nilai TDS masih sangat rendah). Hal ini mengakibatkan pemborosan karena blowdown yang tidak perlu dilakukan (berlebihan). Pengendalian blowdown secara otomatis mendekati nilai TDS yang diinginkan menjadi satu solusi untuk meminimalkan hilang energi, bahan bakar, bahan kimia dan biaya serta konsumsi air umpan boiler.
\end{abstract}

Kata kunci - Boiler, TDS (total dissolved solid), Automatic Blowdown Control System.

\section{PENDAHULUAN}

PT. CentralPertiwi Bahari Fond Site di Lampung merupakan salah satu perusahaan yang bergerak di bidang Food Product yang memproduksi berbagai macam bentuk pengolahan shrimp/udang. Steam merupakan salah satu bahan baku yang digunakan untuk memproses/memasak salah satu jenis produk udang. Selain itu, steam juga digunakan untuk mesin laundry dan dryer pakaian pekerja processing. Steam yang digunakan di PT. CentralPertiwi disupply dari dua unit boiler yaitu HOKEN Boiler dan YORK Boiler, adapun kapasitas steam yang dihasilkan adalah 3000 $\mathrm{kg} / \mathrm{h}$ dan $2000 \mathrm{~kg} / \mathrm{h}$, untuk boiler HOKEN dengan design pressure $10 \mathrm{~kg} / \mathrm{cm}^{2}$ dan test pressure $15 \mathrm{~kg} / \mathrm{cm}^{2}$, dan kondisi operasi boiler 8 barg.
Dalam proses distribusinya Steam yang dihasilkan boiler terkumpul terlebih dahulu di steam header dan selanjutnya dialirkan melalui pipa - pipa dan didistribusikan menuju mesin cooker yang ada di Plant I dan Plant II. Dalam proses produksi steam diboiler dan pendistribusian steam menuju peralatan dan mesin - mesin yang menggunakan steam tersebut terdapat rugi - rugi energi dan membuat boros bahan bakar. Adapun beberapa penyebab terjadinya rugi - rugi adalah hilangnya energi berupa pelepasan panas disepanjang pipa distribusi steam, untuk mengurangi rugi energi pipa - pipa distribusi steam dilapisi dengan insulator aluminium foil dan glass wool. Namun tetap terjadi perpindahan panas yang menyebabkan terjadinya kondensasi sebagian kecil steam dalam pipa, terlebih jarak yang cukup jauh. Maka untuk mengatasi waterhammer yang terjadi karena kondensat dalam sistem steam 
yang terambil oleh steam yang bergerak dan dapat menyebabkan kerusakan pada saluran pipa, maka dipasang strainers dan steam trap.

Selain hal tersebut rugi - rugi juga dapat terjadi dari feed water (pengisi air ketel) masih mengandung kotoran-kotoran (impurities) yang berupa suspensi, garam-garaman, lumpur, maupun padatan-padatan. Kotoran tersebut dapat mengendap dan terakumulasi di dalam boiler apabila boiler beroperasi secara terus-menerus. Peningkatan konsentrat kotoran berupa padatan-padatan yang terlarut dalam air ketel dapat tercampaur dengan uap (steam) sehingga menyebabkan kerusakan pada pipa, steam traps. Adapun peningkatan konsentrat berupa suspensi yang berupa lumpur akan berpengaruh pada efisiensi boiler dan proses heat transfer. Untuk mengatasi permasalahan di atas, maka air dalam boiler perlu dilakukan pembersihan atau "blowdown" secara berkala untuk mengontrol tingkat konsentrat kotoran tersebut di dalam boiler. Blowdown biasanya dilakukan secara berkala untuk mengurangi jumlah padatan terlarut dalam air ketel.

Boiler blowdown yang dilakukan secara periodik sangat penting. Namun, blowdown yang tidak benar dapat menyebabkan peningkatan konsumsi bahan bakar, tambahan perlakuan kimiawi lain (chemical treatment) dan heat loss. Oleh karena itu perlu dilakukan kajian tentang alternatif rencana pemasangan Automatic Blowdown Control system sebagai solusi untuk meminimalkan hilang energi, bahan bakar, bahan kimia dan biaya serta konsumsi air umpan boiler

\section{TINJAUAN PUSTAKA}

\subsection{HOKEN Boiler}

HOKEN Boiler merupakan ketel uap yang menggunakan sistem fire tube boiler (sistem pipa api) horisontal tiga tahap dan diproduksi dibawah lisensi dari K. Hagoort Produktiemij BV, Tilburg - Belanda. Tahap pertama adalah lorong api dan peti api, untuk tahap kedua dan ketiga adalah pipa - pipa api. Gas panas hasil pembakaran akan mengalir melewati lorong api sampai ke peti api, di peti api ini arah dari gas panas akan dibelokkan ke pipa api tahap kedua dan akan mengalir sampai ke kamar asap bagian depan. Pada kamar asap bagian depan, sekali lagi arah gas panas ini akan dibelokkan dan masuk ke pipa api tahap ketiga dan masuk ke kamar asap bagian belakang. Pada kamar asap bagian belakang ini, gas asap akan keluar dari boiler melalui cerobong.

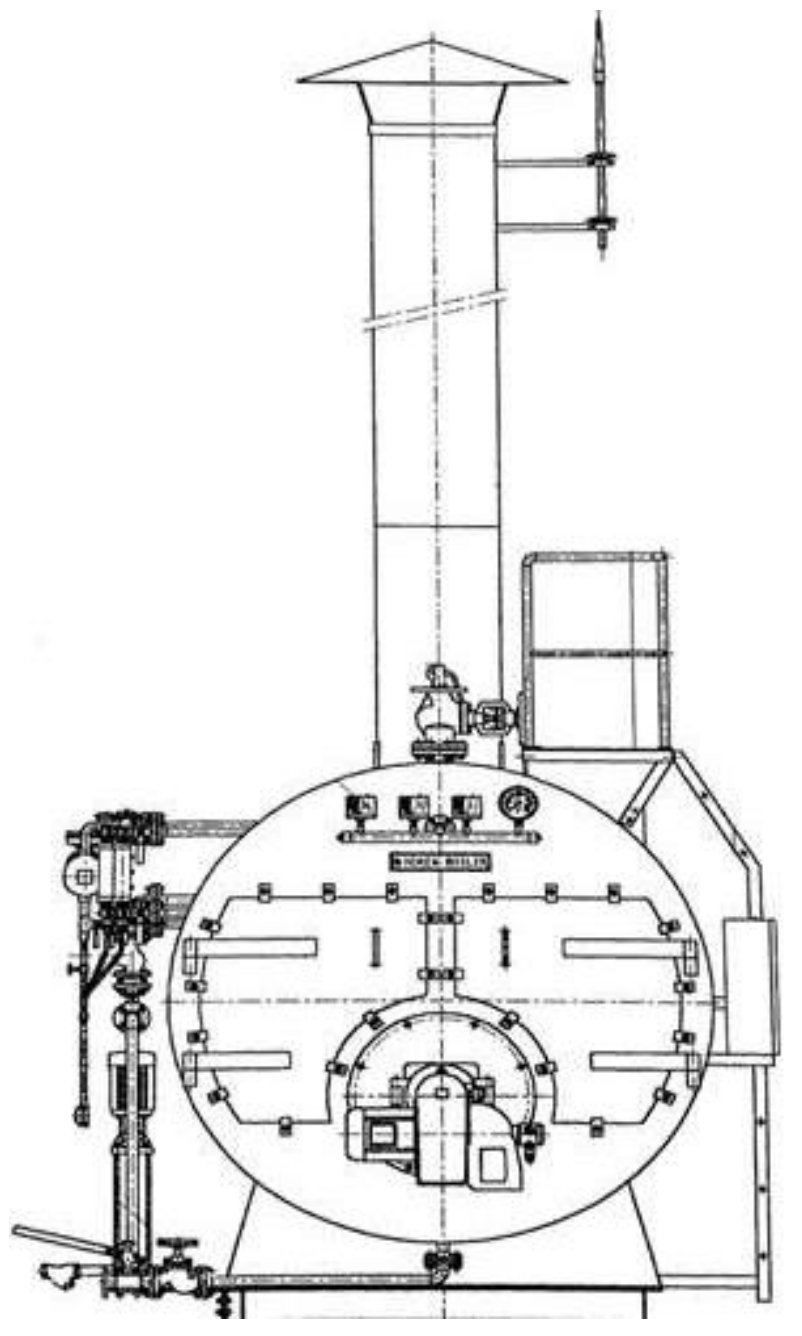

Gambar 1. Tampak Depan HOKEN BOILER Cap. 3000 kg/h

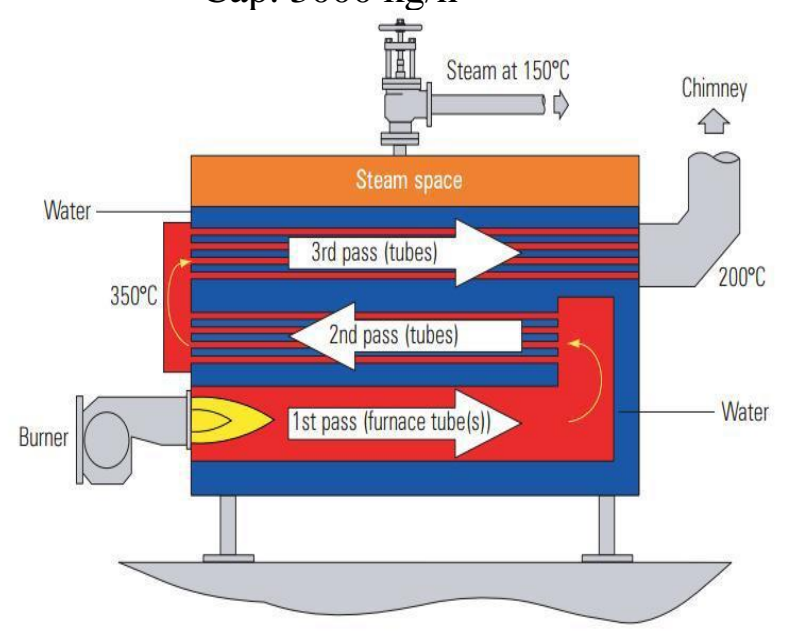

Gambar 2. Sistem pipa api horisontal tiga tahap 
2.2. Nilai Batas Feed Water dan Boiler Water HOKEN Boiler

\begin{tabular}{|c|c|c|}
\hline \multicolumn{3}{|c|}{ Feed Water } \\
\hline $\mathrm{pH}\left(25^{\circ} \mathrm{C}\right)$ & & $8.2 \cdot 9.5$ \\
\hline Hardness & $\mathrm{mgCaCO} / \mathrm{ts}$ & 0.1 \\
\hline Fat & mgilts & None \\
\hline Dissolved Oxygen & $\mathrm{mg} 0 / \mathrm{its}$ & $<0.5$ \\
\hline Total Iron & mgFelits & 0.5 \\
\hline Total Dissolved Solds & $\mathrm{mg} / \mathrm{lt}$ & 350 \\
\hline Suspended Solids & $\mathrm{mg} / \mathrm{ts}$ & 10 \\
\hline $\mathrm{SO}_{2}$ & $\mathrm{mgSiO}_{2} / \mathrm{lt}$ & 10 \\
\hline Chlorine & $\mathrm{mgCT} / \mathrm{tr}$ & 100 \\
\hline m- Akcainity & mgCaCo $/ 1$ th & 180 \\
\hline \multicolumn{3}{|c|}{ Boiler Water } \\
\hline $\mathrm{PH}\left(25^{\circ} \mathrm{C}\right)$ & & $10-12$ \\
\hline m-Alcalinity & $m g C a C o$ /tit & 700 \\
\hline p. Alkalinity & moCaCo/ltr & $250-300$ \\
\hline Total Dissolved Solids & mgilts & 2500 \\
\hline Suspended Solids & (mg/ltr) & 100 \\
\hline Total Hardness & $m g C_{C} C_{y} /$ its & $\begin{array}{c}\text { Not } \\
\text { Detectable }\end{array}$ \\
\hline Total Iron & mgFe/lts & 0.5 \\
\hline Chlorine & $\mathrm{mgC} / \mathrm{lt}$ & 1000 \\
\hline Phospate & $\mathrm{mg}^{2} \mathrm{O}_{4}^{2} / \mathrm{lts}$ & 30.60 \\
\hline Silica & mgsio, 1 tir & 100 \\
\hline Hydrazine & $\mathrm{mgN}_{2} \mathrm{H}_{4} / \mathrm{lt}$ & $0.1-1.0$ \\
\hline Sulphite & $\mathrm{moSO}_{3}^{2} / \mathrm{tr}$ & $30-60$ \\
\hline Hydroxide & $\mathrm{CaCO}_{3}$ & $300-400$ \\
\hline Organics & & $70 \cdot 100$ \\
\hline Electric Conductivity & $1 \mathrm{~s} / \mathrm{cm}$ & $<6000$ \\
\hline
\end{tabular}

Tabel 1. Nilai Batas Feed Water dan Boiler Water HOKEN Boiler

\subsection{Automatic Blowdown Control System}

Komponen Automatic Blowdown Control System yang direncanakan untuk dipasang pada HOKEN Boiler adalah :

- Controller (Wall mounted/Panel mounted)

- Blowdown Valve (pneumatically actuated/electrohydraulically actuated)

- Conductivity probe/sensor

- Probe elbow

- Stop valve

- Check valve

- Sample cooler system

\section{METODA}

Kajian peluang penghematan energi dengan merencanakan pemasangan Automatic Blowdown Control System dari spirax sarco dilakukan dalam beberapa tahap yaitu:

a. Tahap persiapan, dilakukan:

- Persiapan personil

- Persiapan instrument b. Tahap pengambilan data operasional Boiler, dilakukan:

- Pengambilan data Tekanan boiler, temperature air umpan, konsumsi steam, konsumsi steam rata -rata, nilai TDS target, nilai TDS rata - rata dan nilai TDS air umpan.

c. Tahap perhitungan untuk Blowdown secara manual, dilakukan:

- Perhitungan persentase blowdown terhadap air umpan, blowdon pada beban tertinggi, energi menaikkan air umpan , energi penguapan pada tekanan steam boiler dan total konsumsi energi rata-rata.

d. Tahapan perhitungan secara Automatic Blowdown Control System (automatic TDS)

- Perhitungan persentase blowdown terhadap air umpan, blowdon pada beban tertinggi, energi menaikkan air umpan , energi penguapan pada tekanan steam boiler dan total konsumsi energi rata-rata.

e. Tahapan analisis dan kesimpulan.

\section{HASIL DAN PEMBAHASAN}

\subsection{Konsep Planning Instalasi Automatic Blowdown Control System}

Automatic Blowdown Control System BCS3 adalah suatu kontrol otomatis blowdown boiler yang bekerja berdasarkan nilai TDS boiler yang terbaca oleh sensor. Sistem ini akan bekerja sesuai setting nilai TDS (sesuai rekomendasi Boiler Manufacturer) yang kita input pada kontroler, bila nilai TDS pada boiler yang terbaca melebihi dari nilai setting maka secara otomatis sistem akan melakukan blowdown sampai mencapai mencapai nilai TDS yang diatur. Pemasangan blowdown control system pada sisi boiler seperti yang terlihat pada gambar 3 . 


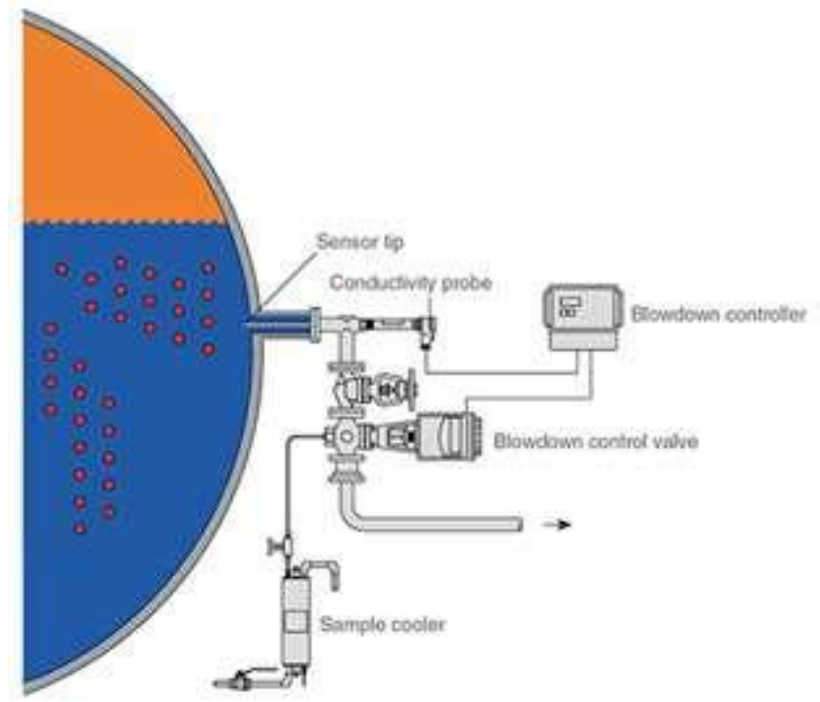

Gambar 3. Instalasi Perangkat Automatic Blowdown Control System (Spirax Sarco)

Pada gambar 3. Terlihat pengukuran TDS melalui sensor tip/ conductivity probe yang tercelup di air boiler bagian samping shell boiler, hasil pembacaan sensor akan dikontrol oleh kontroller BC3200, bila nilai yang terbaca diatas set point maka kontroller akan mengaktifkan blowdown valve untuk terbuka sehingga air akan dibuang sampai nilai TDS dibawah set point.

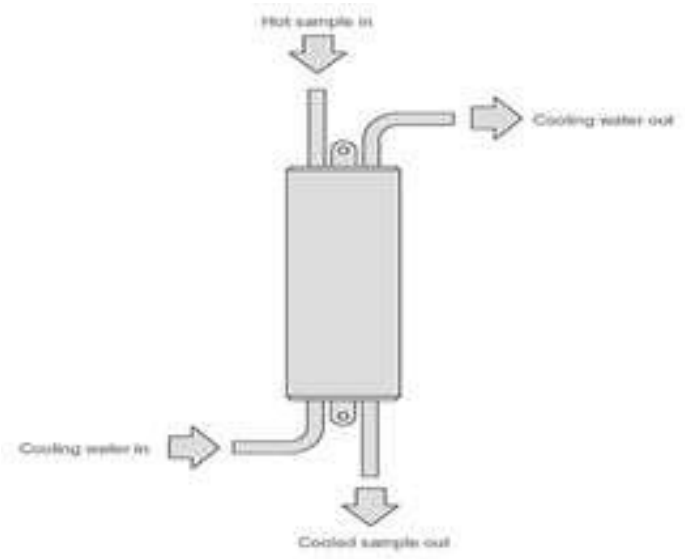

Gambar 4. Sample cooler system

Sample cooler system berfungsi sebagai pendingin air dari boiler yang masih panas, sehingga air sample tersebut bisa di cek dan diukur kadar TDS secara manual juga.

\subsection{Kinerja Penerapan Automatic Blowdown Control System}

Pada gambar 5. Terlihat keuntungan penggunaan blowdown secara otomatis dibandingkan dengan blowdown secara manual.

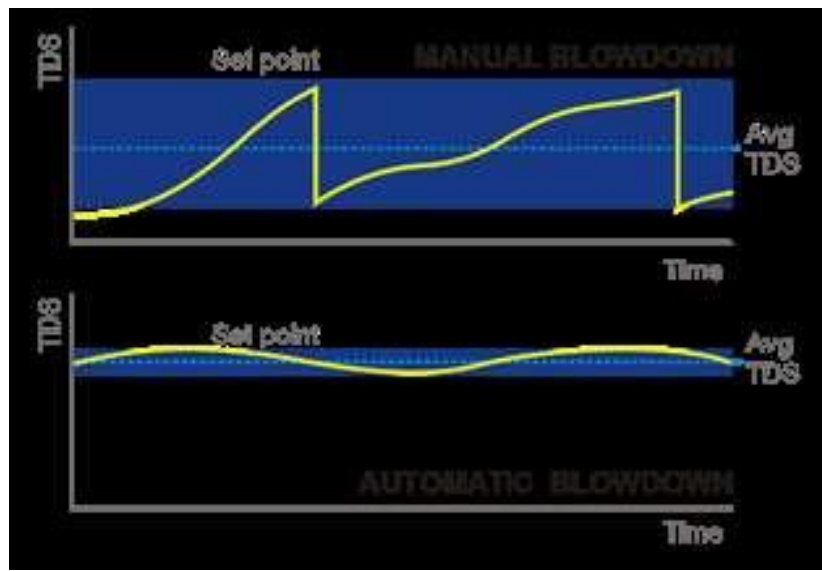

Gambar 5. Perbedaan Plot TDS terhadap waktu antara Manual Blowdown vs Automatic Blowdown

Pada saat manual blowdown terlihat bahwa nilai average TDS secara signifikan jatuh dibawah nilai maximum allowable (set point). Dengan memasang Automatic Blowdown Control System (automatic TDS) nilai average TDS dapat dijaga pada nilai yang sangat mendekati maximum allowable (set point) sehingga mengurangi jumlah blowdown berlebih.

\subsection{Penghematan Energi}

Penghematan energi yang dimaksud adalah selisih total konsumsi energi yang diperlukan untuk memanaskan air umpan boiler sampai temperatur titik didih.

Tabel 2 Data Operasional HOKEN Boiler

\begin{tabular}{|l|l|r|c|}
\hline No & Parameter & Nilai & Satuan \\
\hline 1. & Tekanan steam boiler & 8 & barg \\
\hline 2. & Temperatur air umpan & 70 & ${ }^{\circ} \mathrm{C}$ \\
\hline 3. & $\begin{array}{l}\text { Konsumsi steam } \\
\text { maksimun }\end{array}$ & 3000 & $\mathrm{Kg} / \mathrm{h}$ \\
\hline 4. & $\begin{array}{l}\text { Konsumsi steam rata - } \\
\text { rata (average) }\end{array}$ & 2500 & $\mathrm{Kg} / \mathrm{h}$ \\
\hline 5. & Nilai TDS target & 3000 & $\mathrm{ppm}$ \\
\hline 6. & Nilai TDS average & 2500 & $\mathrm{ppm}$ \\
\hline 7. & Nilai TDS feed water & 400 & $\mathrm{ppm}$ \\
\hline
\end{tabular}




\section{Blowdown Manual (Manual TDS Control)}

a. Persentase blowdown terhadap feed water

$: \frac{\text { Feedwater TDS }}{\text { Average boiler TDS - Feedwater TDS }}$

$: \frac{400}{2.500-400}$

: $19,05 \%$

b. Blowdown pada beban tertinggi

Blowdown rate: $\quad \frac{F \times S}{B-F}$

Dimana;

$\mathrm{F}$ : Feed tank TDS in ppm

$\mathrm{S}$ : Actual boiler steam production in $\mathrm{kg} / \mathrm{hr}$

B : Maximum TDS allowable in the boiler in ppm

$: \frac{400 \times 3.000}{2.500-400}$

: $571 \mathrm{~kg} / \mathrm{h}$

c. Blowdown pada beban rata - rata (average)

$: \frac{400 \times 2.500}{2.500-400}$

: $476 \mathrm{~kg} / \mathrm{h}$

d. Flow rate air ke boiler pada beban tertinggi :

$: \frac{3.000 \mathrm{~kg} / \mathrm{h} *(100+19,05)}{100}$

: $3.571 \mathrm{~kg} / \mathrm{h}$

e. Flow rate air ke boiler pada beban rata - rata :

$: \frac{2.500 \mathrm{~kg} / \mathrm{h} *(100+19,05)}{100}$

: $2.976 \mathrm{~kg} / \mathrm{h}$

Temperatur air umpan (feed water) akan dinaikkan ke temperatur jenuh (saturation). Dari steam tables didapat water sensible heat/temperatur air umpan (hf : $743 \mathrm{kj} / \mathrm{kg}$ pada 8 bar g) ke saturated liq/temperatur saturasi (hf : $293 \mathrm{kj} / \mathrm{kg}$ pada $70^{\circ} \mathrm{C}$ ) f. Energi untuk menaikkan temperatur air umpan (pada flowrate rata-rata) :

$: \frac{2.976 \mathrm{~kg} / \mathrm{h} *(743-293) \mathrm{kj} / \mathrm{kg}}{3.600 \mathrm{sec} / \mathrm{h}}$

: $372 \mathrm{kw}$

g. Energi penguapan (pada beban steam boiler rata-rata) hfg : $2031 \mathrm{kj} / \mathrm{kg}$ pada 8 bar g (steam tables)

$: \frac{2.500 \mathrm{~kg} / \mathrm{h} * 2.031 \mathrm{kj} / \mathrm{kg}}{3.600 \mathrm{sec} / \mathrm{h}}$

: $1.410 \mathrm{kw}$

h. Total energi yang diperlukan untuk menghasilkan $2.500 \mathrm{~kg} / \mathrm{h}$ steam adalah :

: $372 \mathrm{kw}+1.410 \mathrm{kw}$

: $1.782 \mathrm{kw}$

\section{Automatic Blowdown (Automatic TDS)}

a. Persentase blowdown terhadap feed water

Feedwater TDS

: $\overline{\text { Max.Allowable TDS - Feedwater TDS }}$

$: \frac{400 * 100 \%}{3.000-400}$

: $15,4 \%$

b. Flow rate air ke boiler pada beban rata - rata :

$: \frac{2.500 \mathrm{~kg} / \mathrm{h} *(100+15,38)}{100}$

: $2.885 \mathrm{~kg} / \mathrm{h}$

c. Energi untuk menaikkan temperatur air umpan (pada flowrate rata-rata) :

$: \frac{2.885 \mathrm{~kg} / \mathrm{h} *(743-293) \mathrm{kj} / \mathrm{kg}}{3.600 \mathrm{sec} / \mathrm{h}}$
$: 361 \mathrm{kw}$ 
d. Energi penguapan (pada beban steam boiler rata-rata) hfg : $2031 \mathrm{kj} / \mathrm{kg}$ pada 8 bar g (steam tables)

$$
: \frac{2.500 \mathrm{~kg} / \mathrm{h} * 2.031 \mathrm{kj} / \mathrm{kg}}{3.600 \mathrm{sec} / \mathrm{h}}
$$

: $1.410 \mathrm{kw}$

e. Total energi yang diperlukan untuk menghasilkan $2.500 \mathrm{~kg} / \mathrm{h}$ steam adalah :

: $361 \mathrm{kw}+1.410 \mathrm{kw}$

: $1.771 \mathrm{kw}$

\section{REFERENSI}

[1] Kameshwar Upadhyay, Hands on Boiler and aux Operation and Manitenance,Notion Press, 2017.

[2] K. Hagoort, "Buku Pedoman dan Pemeliharaan Hoken Boiler," Grand Kartech, 1996.

[3] Michael Carr, Dr. Rainer Höcker, Dr. Ian Roberts, Romeo Rocchetti, Oliver Seifert, Thomas Stauss, Phillip Stoor, Steam Handbook An introduction to steam generation and distribution, Endress+Hauser Flowtec AG, CH4153 Reinach/BL, 2017.

[4] Spirax Sarco in House Training, "Basic steam engineering and control valve and instrumentations" PT. Petrolog Multi Usaha Mandiri, 2005.

\section{KESIMPULAN}

Hasil perhitungan menunjukkan bahwa ketika dilakukan blowdown secara manual didapat persentase blowdown terhadap air umpan (feed water) sebesar $19,05 \%$ dan konsumsi energi sebesar $1.782 \mathrm{kw}$. Pada saat menggunakan automatic blowdown ( automatic TDS) didapat persentase blowdown terhadap air umpan (feed water) sebesar $15,4 \%$ konsumsi energi sebesar $1.771 \mathrm{kw}$. Sehingga didapat penghematan energi:

- Persentase blowdown terhadap air umpan

: $19,05 \%-15,4 \%$

: $3,65 \%$

- Penghematan energi

: $1.782 \mathrm{kw}-1.771 \mathrm{kw}$

: $11 \mathrm{kw}$

Faktor - faktor pendukung seperti steam trap, insulasi pipa steam, strainer dan lainnya harus tetap terawat, dan agar boiler tetap efisien, air umpan/feed water harus tetap dijaga kualitas dan suhunya serta secara berkala fire tube /pipa api dan lorong api di dalam boiler harus dibersihkan sehingga heat transfer tetap maksimal. 